\title{
Subjectivity Study on Smartphone Addiction in Nursing Students
}

\author{
Sunyoung Jang \\ Department of Nursing, Hanseo University, 46 Hanseol Ro, Haemi-myun, Seosan-si, \\ Chungcheongnam-do, 369-709, Korea \\ sjang@hanseo.ac.kr
}

\begin{abstract}
The purpose of this study is to identify the subjectivity of smartphone addiction recognized by nursing students, describe the characteristics of each type, and identify the typology of smartphone addiction, and $Q$ methodology was applied. 20 students in the department of nursing at A University were asked to classify 46 statements on smartphone addiction. Collected data were analyzed using the QUANL PC Program. In this study, the perception of smartphone addiction by nursing students was classified into 3 factors. Subjectivity types for smartphone addiction are 'cause-oriented type', 'result-oriented type', and 'physical harm concern type'. This study provided basic data on education related to nurses as female workers and the nursing of female patients in the maternity parenting cycle.
\end{abstract}

Keywords: Smartphone addiction, Nursing student, Subjectivity, Q methodology, Nurse

\section{Introduction}

\subsection{Necessity of study}

The definition of smartphone addiction is not clear, but it is defined that the interest outside the smartphone decreases and the usage time of the smartphone increases, so that if the smartphone is not in the hands, withdrawal phenomenon occurs and people suffer insecurity, restlessness and are unable to concentrate on other things [1]. Appropriate use of smartphones allows for more free communication, easier access and sharing of information, and adds convenience and interest to our lives. However, the excessive use of smartphones is causing people to rely on or obsess with their smartphones, and dysfunction of the smartphone is also created such as when people have to increase their smartphone usage time, or they feel uneasy when they don't use the smartphone [2].

While there is still a lack of an accurate understanding of the process and the causal factors of smartphone addiction, some researchers described the cause of smartphone addiction as negative emotions and interpersonal difficulties [3]. In addition, it is reported that the smartphone addiction phenomenon causes problems in mental health, interpersonal relationships, and school life [4], and psychological and psychological factors are reported to have a significant effect on the addiction phenomenon [5]. This also causes physical problems, especially musculoskeletal disorders such as myofascial pain syndrome,

Article history:

Received (April 7, 2019), Review Result (May 4, 2019), Accepted (June 29, 2019) 
epicondylitis, and carpal tunnel syndrome, and while it is conveniently used in daily life, various problems are on the rise [6].

Therefore, this study will explore and typify the awareness of smartphone addiction in nursing students who are prospective nurses. By exploring the characteristics and differences by type of recognition for smartphone addiction, the study attempts to provide basic data necessary to educate nursing students and nurses exposed to smartphone addiction risk.

\subsection{Purpose of study}

The purpose of this study is to investigate the subjective perception type and characteristics of smartphone addiction of nursing students by applying Q-method, and it is intended to provide basic data in presenting strategies for educating nursing students and nurses at risk of smartphone addiction. Specific research objectives for this are as follows.

1) Typify subjective perception of smartphone addiction in nursing students.

2) Analyze and describe the characteristics of types of perceptions of smartphone addiction in nursing students.

\section{Method of study}

\subsection{Design of the study}

To achieve the purpose of the study, after reviewing the literature, media materials, and previous studies on smartphone addiction, the study aimed to find subjectivity in exploring the types of subjective perceptions of smartphone addiction in nursing students who have experienced smartphone addiction.

\subsection{Q population and $Q$ sample selection}

The Q population was drawn through domestic and international literature reviews, open questionnaires, and in-depth interviews to extract comprehensive statements on the effects of smartphone addiction, focusing on current nursing students. Through this process, around 200 Q populations were derived from 3 domains, and in addition, a total of $100 \mathrm{Q}$ populations were extracted by integrating the literature collected through relevant domestic and international literature studies. After reviewing and revising the extracted Q sample of this study, the final 46 samples with high discrimination were selected.

\subsection{Design of the study}

Q-methodology is qualitative research that emphasizes individual inertia by focusing on differences in meaning or importance within an individual, not on individual differences and it is based on the small sample doctrine that the larger the P sample is, the more people are biased in one factor and the characteristics are not revealed [7] The P sample of this study selected were total of 20 people who have fully explained the purpose of the study who were students in a nursing department and agreed to participate in the study through voluntary consent.

\subsection{Classification and data analysis method}

The Q classification process is a process by which individuals selected as $\mathrm{P}$-samples make a voluntary definition of smartphone addiction by classifying the Q-sample statements into a 
forced normal distribution method. The study collected data using a Q card for 20 students in the department of nursing at OO University. The length of time for each subject to complete the Q-classification was mostly 30-45 minutes. The distribution of Q samples categorized the statements selected by the study subjects as Q samples from strong positive to strong negative according to the importance of their opinion. The statement on smartphone addiction (Q1) was classified on a 12-point scale. Subsequently, further interviews were conducted with the subject regarding the statements classified at both ends. Q factor analysis was based on Principle Component Factor Analysis (varimax). The classification of the type was selected in consideration of the result calculated by inputting the number of factors based on Eigenvalue 1.0 or higher and the total explanatory variable. The collected data were scored by converting points assigned to each of 1-12 points, centered on the cards forcibly distributed in the $Q$ sample distribution table. The assigned conversion scores were coded in the order of $\mathrm{Q}$ sample number and processed by principal factor analysis by QUANL PC Program.

\subsection{Ethical considerations for the subject}

It was explained to the subjects that they can stop at any time during the study, after seeking voluntary consent from the subjects before the study. To respect the rights of the subjects and to ensure the privacy and confidentiality of the subjects, all information collected through this study was treated anonymously throughout the data analysis, and it was coded and Q sorted to ensure confidentiality.

\section{Result of the study}

\subsection{Subjectivity and type-specific characteristics in smartphone addiction}

Q-factor analysis of subjectivity on smartphone addiction by nursing students using the QUANL pc program revealed 3 types.

\subsection{Type-specific characteristics in smartphone addiction}

Cause-Oriented Type: The subjects of type 1 consisted of 5 persons. Statements with a strong positive response in type 1 subjects were, 'I feel a sense of belonging in the interpersonal relationship through smartphone SNS.( $Z=1.85)^{\prime}$ ', 'Pleasure is met through using a smartphone. $(\mathrm{Z}=1.73)$ ', and 'Using smartphones became a habit. $(\mathrm{Z}=1.69)$ ' [Table 1]. In type 1 , the subject with the highest factor weight was 12 (5.2691), and the most agreed statement were 45 and 44 . Statements with strong negative responses in type 1 subjects were, 'Smartphone addiction leads to more involvement in antisocial and illegal activities. ( $\mathrm{Z}=-$ 2.05 )', 'Smartphone addiction reduces career worries. ( $\mathrm{Z}=-1.88)$ ', and 'Smartphone addiction makes me more satisfied with virtual worlds than with real life. $(Z=-1.75)$ ' [Table 1]. In type 1 , the subject with the lowest factor weight was 3 (1.2427), and the most disagreed statements were 11 and 15. The characteristics of type 1 are to focus on the causes that become smartphone addiction. They think that smartphone addiction occurs because it meets the insufficient needs of individuals through a smartphone or escapes to virtual space, and think removing the cause is a way to prevent smartphone addiction. They believe that smartphone addiction will be inevitable because it can satisfy unmet needs in real human relationships. Therefore, type 1 was named 'cause oriented type'.

Result-Oriented Type: The subjects of type 2 consisted of 8 persons. Statements with a strong positive response in type 2 subjects were, 'Using smartphones became a habit. 
( $\mathrm{Z}=2.23)$ ', 'Carpal tunnel syndrome occurs due to smartphone addiction. ( $\mathrm{Z}=1.97)$ ', and 'Smartphone addiction causes sleep deprivation. ( $Z=1.94)$ ' [Table 1]. In type 2, the subject with the highest factor weight was 5 (1.1530), and the most agreed statement were 46 and 24. Statements with strong negative responses in type 2 subjects were, 'Smartphone addiction may lead to involvement in the crime. $(Z=-2.19)$ ', 'Smartphone addiction reduces career worries. $(Z=-1.86)$ ', and 'Smartphone addiction makes me more satisfied with virtual worlds than with real life. $(Z=-1.56)^{\prime}$ [Table 1]. In type 2, the subject with the lowest factor weight was 15 (0.4227), and the most disagreed statements were 32 and 15 . The characteristics of type 2 are that they focus on the physical, mental, and social side effects that can be caused by smartphone addiction. carpal tunnel syndrome, they were concerned about lack of sleep, dry eyes, decreased eyesight, and deterioration of interpersonal belonging. They thought, however, that the drawbacks of smartphone addiction were not linked to felony-level crimes that would cause social strain. Therefore, they said that such side effects can be easily overcome and recovered. Therefore, type 2 was named 'result-oriented type'.

Table 1. Representative items on smartphone addiction and Z-score $(\mathrm{N}=20)$

\begin{tabular}{|c|c|c|c|c|}
\hline Factor & No & Description & Mean (SD) & Z-score \\
\hline \multirow{6}{*}{$\begin{array}{l}\text { Factor } 1 \\
(\mathrm{~N}=5)\end{array}$} & 45 & $\begin{array}{l}\text { I feel a sense of belonging in the interpersonal } \\
\text { relationship through smartphone SNS. }\end{array}$ & $10.60(2.608)$ & 1.85 \\
\hline & 44 & Pleasure is met through using a smartphone. & $10.60(1.517)$ & 1.73 \\
\hline & 46 & Using smartphones became a habit. & $10.20(2.490)$ & 1.69 \\
\hline & 11 & $\begin{array}{l}\text { Smartphone addiction leads to more involvement in } \\
\text { antisocial and illegal activities. }\end{array}$ & $1.60(1.342)$ & -2.05 \\
\hline & 15 & Smartphone addiction reduces career worries. & $1.60(1.673)$ & -1.88 \\
\hline & 20 & $\begin{array}{c}\text { Smartphone addiction makes me more satisfied with } \\
\text { virtual worlds than with real life. }\end{array}$ & $2.00(0.707)$ & -1.75 \\
\hline \multirow{6}{*}{$\begin{array}{l}\text { Factor } 2 \\
(\mathrm{~N}=8)\end{array}$} & 46 & Using smartphones became a habit. & $10.75(2.435)$ & 2.23 \\
\hline & 24 & $\begin{array}{c}\text { Carpal tunnel syndrome occurs due to smartphone } \\
\text { addiction. }\end{array}$ & $9.75(2.550)$ & 1.97 \\
\hline & 28 & Smartphone addiction causes sleep deprivation. & $10.13(0.991)$ & 1.94 \\
\hline & 32 & $\begin{array}{l}\text { Smartphone addiction may lead to involvement in } \\
\text { the crime. }\end{array}$ & $2.25(1.669)$ & -2.19 \\
\hline & 15 & Smartphone addiction reduces career worries. & $3.50(3.546)$ & -1.86 \\
\hline & 20 & $\begin{array}{l}\text { Smartphone addiction makes me more satisfied with } \\
\text { virtual worlds than with real life. }\end{array}$ & $3.25(1.488)$ & -1.56 \\
\hline \multirow{6}{*}{$\begin{array}{c}\text { Factor } 3 \\
(\mathrm{~N}=7)\end{array}$} & 24 & $\begin{array}{l}\text { Carpal tunnel syndrome occurs due to smartphone } \\
\text { addiction. }\end{array}$ & $9.43(2.760)$ & 2.03 \\
\hline & 37 & $\begin{array}{c}\text { Smartphone addiction causes dry eye and decreased } \\
\text { vision. }\end{array}$ & $8.86(2.340)$ & 1.80 \\
\hline & 36 & $\begin{array}{c}\text { Due to the overuse of smartphones, brain cell } \\
\text { damage may occur. }\end{array}$ & $8.43(1.988)$ & 1.37 \\
\hline & 15 & Smartphone addiction reduces career worries. & $2.43(1.134)$ & -2.31 \\
\hline & 44 & Pleasure is met through using a smartphone. & $3.86(2.734)$ & -1.83 \\
\hline & 34 & $\begin{array}{l}\text { I am aware of smartphone addiction but cannot fix } \\
\text { it. }\end{array}$ & $4.14(2.193)$ & -1.62 \\
\hline
\end{tabular}

Physical Harm Concern Type: The subjects of type 3 consisted of 7 persons. Statements with a strong positive response in type 3 subjects were, 'Carpal tunnel syndrome occurs due to smartphone addiction. ( $\mathrm{Z}=2.03)$ ', 'Smartphone addiction causes dry eye and decreased vision. $(\mathrm{Z}=1.80)$ ', and 'Due to overuse of smartphones, brain cell damage may occur. $(\mathrm{Z}=1.37)$ ' [Table 1]. In type 3, the subject with the highest factor weight was 4 (1.0334), and the most 
agreed statement were 24 and 37. Statements with strong negative responses in type 3 subjects were, 'Smartphone addiction reduces career worries. $(Z=-2.31)$ ', 'Pleasure is met through using a smartphone. ( $\mathrm{Z}=-1.83)$ ', and 'I am aware of the smartphone addiction but cannot fix it. ( $Z=-1.62)$ ' [Table 1]. In type 3, the subject with the lowest factor weight was 18 (0.2511), and the most disagreed statements were 15 and 44 . The characteristics of type 3 were that they were concerned about the physical side effects that smartphone addiction could bring, and thought that it was difficult to reverse the physical harm that occurred. carpal tunnel syndrome, They believed that it could lead to dry eyes and poor vision, as well as permanent brain cell damage. Furthermore, they judged that smartphone addiction would become more and more serious and that normal life would not be easy. They were concerned that various harms caused by smartphone addiction would make daily life difficult. Therefore, type 3 was named the 'physical harm concern type'.

\section{Discussion}

As a result of this study, the subjectivity types of smartphone addiction recognized by nursing students were found to be type 1 'cause oriented type', type 2 'result-oriented type', and type 3 'physical harm concern type', and the study will discuss the characteristics of each type accordingly.

Type 1 in this study was 'cause oriented type'. They focus on the cause of smartphone addiction. They believe that smartphone addiction is a refuge due to lack of something or difficulty in life.

Type 2 was the 'result-oriented type'. Subjects of this type were concerned about side effects in various areas that result from smartphone addiction. However, these subjects did not think that these side effects would make their daily lives impossible and that they would be able to recover if they were removed from their smartphone addiction.

Type 3 was the 'physical harm concern type'. They thought that the physical side effects caused by smartphone addiction could be irreparable and cause serious damage. Therefore, they think that smartphone addiction should be dealt with carefully, prevented, and educated about physical side effects.

This study explored the nursing students' subjective perception of smartphone addiction, and then analyzed it by dividing it into three types. Based on the characteristics of each type, it was divided into 'cause-emphasis type' preferentially considering the causes for smartphone addiction, 'result-emphasis type' considering such minor and recoverable side effects shown after smartphone addiction, and 'physical damage concern type' worrying about unrecoverable physical side effects caused by smartphone addiction. This study on subjectivity would be used as the basic data for the development of smartphone preventative programs that have recently grabbed attention. Moreover, it would be possible to apply effective education methods suitable for each type in the case when new and experienced nurses provide education to smartphone addicts in the future.

However, this study just targeted a university and did not consider the factors having effects on the perception of smartphone addiction when selecting the subjects, so it would be limited to generalize the results of this study. Therefore, the follow-up researchers need to additionally verify the types by composing the $\mathrm{Q}$ sample with diverse backgrounds.

\section{Conclusion}

The study explored subjective perceptions of smartphone addiction of nursing students and through the analyzed subjective data, an attempt was made to apply the Q methodology to 
prepare the basic data necessary to develop a training program for the prevention of smartphone addiction among nursing students and the management of the subjects of clinical nurses. The result of the study showed 3 types. Types of smartphone addiction recognized by nursing students were 'cause oriented type', 'result-oriented type', and 'physical harm concern type'.

This study provided the basic data for developing the prevention and improvement program for smartphone addiction of nursing students by categorizing the subjectivity of smartphone addiction of nursing students. It could also provide a theoretical framework for new nurses and nurses to clinically develop individualized educational plans for smartphone addiction subjects.

Further research on the development of smartphone addiction intervention programs for nursing students will be needed based on this study. In addition, follow-up studies on the subjectivity of smartphone addiction perceived by nursing students are needed, and education program development according to this is required.

\section{References}

[1] M-Y. Lee, "Association analysis of smartphone addiction and mild cognitive impairment in college student," Journal of Korea Entertainment Industry Association, vol.9, no.4, pp.361-368, (2015)

[2] HJ Jang and YJ Kwag, "Comparison of factors associated with smartphone over-usage: Focusing on selfcontrol, mental health, and interrelationship," Korea Academia-Industrial cooperation Society, vol.16, no.1, pp.146-154, (2015) DOI: 10.5762/KAIS.2015.16.1.146

[3] S-H. Cho, and G-S. Jeon, "Correlates of problematic mobile phone use among Korean college students," The Korean Journal of Stress Research, vol.24, pp.13-22, (2016) DOI: 10.17547/kjsr.2016.24.1.13

[4] H-S. Choi, H-K. Lee, and J-H. Ha, "The influence of smartphone addiction on mental health, campus life, and personal relations - Focusing on k university students," Journal of the Korean Data \& Information Science Society, vol.23, no.5, pp.1005-1015, (2012) DOI: 10.7465/jkdi.2012.23.5.1005

[5] M-S. Lee, "Smartphone addiction and related social concerns," Unpublished master's thesis, Yonsei University, (2011)

[6] Y-J. Moon, "Change of upper extremity muscle on the hourly with smart-phone use - focused on muscle activity and median frequency," Journal of Korea Entertainment Industry Association, vol.9, no.3, pp.341348, (2015)

[7] S. M. Whang, S. W. You, J. Y. Kim, and R. G. Kim, "Consumer types and cultural consumption characteristics of Korean society: Who spends for what reasons?” Journal of Human Subjectivity, vol.13, pp.25-39, (2006) 